\title{
Calyx Juice of Hibiscus sabdariffa Linn (Malvaceae): A Possible Therapeutic Supplement to Antiretroviral Drugs
}

\author{
Franklin Nyenty Tabe ${ }^{1}$, Nicolas Njintang Yanou ${ }^{1,2}$, Armel Hervé Nwabo Kamdje ${ }^{1}$, \\ Aurélie-Solange Agume Ntso ${ }^{3,4}$ \\ ${ }^{1}$ Department of Biomedical Science, Faculty of Science, University of Ngaoundere, Adamawa Region, Cameroon \\ ${ }^{2}$ National Advanced School of Agro-Industrial Sciences (ENSAI), University of Ngaoundere, Adamawa Region, Cameroon \\ ${ }^{3}$ Department of Food Engineering and Quality Control, University Institute of Technology, Ngaoundere, Adamawa Region, Cameroon \\ ${ }^{4}$ The Adamawa Regional Hospital, Ngaoundere, Cameroon
}

\section{Email address:}

tabef@yahoo.com (F. N. Tabe), njintang@yahoo.fr (N. N. Yanou), kamdjewa@yahoo.fr (A. H. N. Kamdje)

\section{To cite this article:}

Franklin Nyenty Tabe, Nicolas Njintang Yanou, Armel Hervé Nwabo Kamdje, Aurélie-Solange Agume Ntso. Calyx Juice of Hibiscus sabdariffa Linn (Malvaceae): A Possible Therapeutic Supplement to Antiretroviral Drugs. Journal of Diseases and Medicinal Plants. Vol. 1, No. 4, 2015, pp. 59-67.doi: 10.11648/j.jdmp.20150104.12

\begin{abstract}
More than three decades after its outbreak, the Acquired Immune Deficiency Syndrome (AIDS) remains a great mystery because there is neither an existing vaccine against its causative agent (the human immune deficiency virus) nor a cure against it. Worst of all is the popular attention that is tuned to the AIDS virus, ignoring oxidative stress which is the major cause of mortality in HIV/AIDS as in many other chronic diseases. Antiretroviral drugs introduced in 1996 have been shown to increase oxidative stress among other drug-related complications. With these backdrops, an antioxidant therapy is necessary to accompany antiretroviral treatment without which its beneficial effects are null. The present review aims to discuss the role of Calyx juice of Hibiscus sabdariffa Linn (Malvaceae) as a possible therapeutic supplement to antiretroviral drugs.
\end{abstract}

Keywords: Oxidative Stress, Antioxidants, Hibiscus sabdariffa Linn

\section{Introduction}

Hibiscus sabdariffa Linnaeus is an annual shrub that is widely cultivated in the tropical regions of the world, usually between the months of April and November. In some areas around the world, it is cultivated as a home garden crop; cultivation is done using the seeds, rooting or shoot cuttings on a well-drained soil (root and stem rot occur when water content in an irrigated field is not checked), with an annual rainfall of 130-260 $\mathrm{mm}$ in the first 3-4 months of growth. The plant is tolerant to warm and humid climate. Dry weather is favorable during the later months of growth. Root and stem rot, major problem of Roselle cultivation are prevented by monitoring the water content in irrigated fields and by avoiding mixed cultivation with other crops that are susceptible to root and stem rot.

Natural antioxidants are primarily found in plants, mostly in such plant products like fruits and vegetables. Animals depend on plant-based products to obtain antioxidants, but animal-derived products contain insignificant amounts compared to plants. Natural antioxidants come from plantbased products like fruits, vegetables, cereals and legumes, beverages and spices and animal derived foods. In this review, the role of Calyx juice of Hibiscus sabdariffa Linn (Malvaceae) as a possible therapeutic supplement to antiretroviral drugs will be herein summarized and discussed.

\section{Oxidative Stress}

The human body is made up of various defense systems among which is the antioxidant defense system. This system is made of substances of both endogenous (enzymes and intracellular molecules like glutathione) and exogenous (vitamins, micronutrients and phytochemicals) origins. These substances are characterized by their ability to delay or inhibit the destruction of cellular components by free radicals, paramagnetic substances with which they are in equilibrium under healthy conditions. In pathological situations, the antioxidant capacity of cells to scavenge the excess production of reactive oxygen species falls short, leading to the overwhelming of the balance between reactive oxygen species (ROS) and the antioxidant system in favor of the reactive oxygen species in a condition known as oxidative stress $[10,11,12]$. This situation is the consequence of 
excessive metabolism occurring inside the host system [13, $14]$.

\subsection{Free Radicals}

Free radicals are paramagnetic molecular species with one or more unpaired electrons in their outermost shell $[15,16]$ and are important intermediates in natural processes involving cytotoxicity, control of vascular tone, and neurotransmission [17]. This electronic imbalance makes them highly unstable and as a result, they tend to abstract an electron from nearby molecules to attain some stability [15]. The three major reactive oxygen species that are of physiological significance are superoxide anion, hydroxyl radical, and hydrogen peroxide [10].

\subsection{Origins of Free Radicals}

Free radicals are usually from various sources, that may be endogenous (e.g.O2-, $\mathrm{H} 2 \mathrm{O} 2, \mathrm{OH}^{*}, \mathrm{NO}, \mathrm{HOCl}$ etc.), or present in the environment (e.g. RNOS in cigarette smoke) $[14,18]$. Endogenous free radicals originate from metabolic processes, stressful events and ageing, while pollution, dietary factors (food additives, alcohols, grilled, fried, browned or burned foods, hydrogenated vegetable oils, etc.), toxins (e.g. carbon tetrachloride, paraquat) and drugs (e.g. Adriamycin, bleomycin, chlorpromazine) account for the exogenous sources of free radicals generation [17].Also, vigorous physical exercise has been found to raise the free radical status of the body [17].

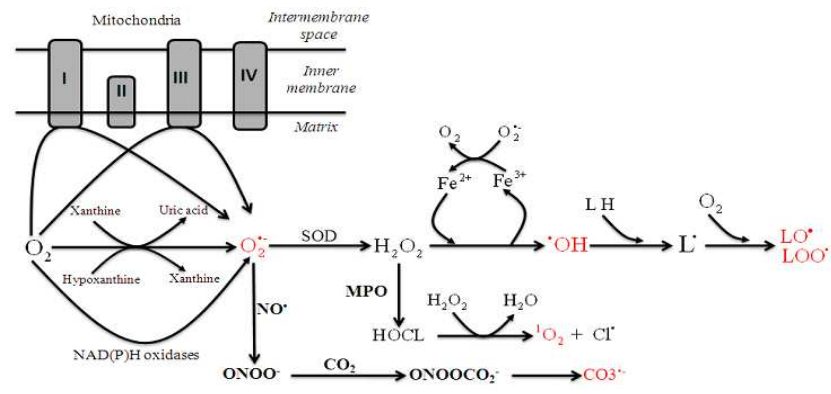

Figure 1. Different routes of production of free radicals [19, 20].

\subsection{Free Radicals in Normal Physiology}

In moderate concentration, free radicals are indispensable to a wide spectrum of biological processes [21]. In most enzymatic reactions, catalysis involves electron transfer and so, the catalytic cycle passes through free radical intermediates [15]. A remarkable area of free radical use is in the defense mechanism of monocytes (macrophages and neutrophils) during immune response to pathogens. Following infection, monocytes (macrophages and neutrophils) generate $\operatorname{ROS}[15,19]$. At rest, neutrophils for example consume very little oxygen during glycolysis; however, this oxygen consumption increases too many folds (respiratory burst) during phagocytosis [15, 17, and 14]. With the glycolytic pathway highly provisioned, its terminal products already in excess retro inhibit its key enzymes such that excess of activated glucose is diverted to the hexose monophosphate shunt (HMS) that produces NADPH. NADPH oxidase in the leukocyte membrane reduces excesses of the molecular oxygen to superoxide, which, through the intermediary of hydrogen peroxide, is transformed into hypochlorous acid $(\mathrm{HOCl})$, a potential toxin to microbes $[15,17]$. Another free radical, nitric oxide (NO) formed from the action of NO synthase on arginine, is highly documented for playing in signal transduction pathways. On the walls of vascular smooth muscles, covalent modification of adenylate cyclase by NO-binding triggers a series of redox reactions that lead to vasodilation $[14,17,22]$. Besides, most non-adrenergic non-cholinergic (NANC) neurons are activated in the same way as vascular smooth muscles [22].

\subsection{Oxidative Stress and Cellular Death}

Several pathological conditions have been revealed to be the consequence of oxidative stress, which is secondary to infections and life styles of individuals. Cellular death or apoptosis is a normal phenomenon that enables the elimination of worn out cells and tissues. However, under conditions of oxidative stress, cellular death no longer follows the natural principles and so there results an imbalance between the rate of cells death and replacement. This results in wasting and a number of age-related diseases such as Alzheimer disease, Parkinson disease and AIDS. Much research work has documented the mechanism of this induced apoptosis on three major biological molecules: DNA, proteins and lipids. For the membrane lipids, the hydroxyl radical initiates chain reactions at the level of polyunsaturated fatty acids by first abstracting a hydrogen atom from the side chain of a polyunsaturated fatty acid [23]. The chain reactions lead to the formation of lipid free radicals and peroxides, which invariably damages the molecular structure of membrane lipids, including those of the defense cells [14]. The membrane thus loses its regulatory functions, leading to uncontrollable influx and efflux of various substances and consequently cell death. In proteins, hydroxyl radical attack on nucleophile centers on the side chains of such amino acids as proline, histidine, cysteine, etc. can be deleterious. The products of oxidative damage may fragment, increasing the susceptibility of the protein to digestion; they may cross-link with one another and produce aggregates that are resistant to digestion [14]. When this happens to membrane proteins for example, they lose their physiological functions in signal transduction with significant consequences to the cell. For the DNA molecule, free radical attacks have been shown to be at the origin of base alterations and strand breaks, leading to various cancers and mutations.

Of which contribute to accumulation of free radicals [7] due to blockage of key reactions of the electron transport chain [38] especially those of complexes I and III.

The pitfalls of antiretroviral drugs in the management of AIDS have stimulated much research in the domain of nonconventional medicine. This has been welcomed by the western biomedicine upon realization of certain advantages it offers especially in supplementing biomedicine in certain 
situations. Much of AIDS-related research is currently focused on seeking plant products that curb oxidative stressrelated deaths, as oxidative stress has been revealed to be the principal cause of mortality in this pandemic as in many other chronic diseases. Many plants have recently been revealed to be rich sources of antioxidants.

\section{Antioxidants}

Antioxidants are either natural or synthetic molecules that inhibit free radical-induced damage to biological molecules by preventing their formation, scavenging them, or enhancing their decomposition [25, 39]. Their neutralizing potential lies in their ability to donate an electron to a reactive oxygen species (ROS), reducing it to a less harmful species [25].

\subsection{Classes of Antioxidants}

There are three main classes of antioxidants which are enzymes, vitamins and phytochemicals. The above three classes are enumerated because of their direct implication in the antioxidant process. In other literatures, micronutrients ( $\mathrm{Zn}, \mathrm{Se}, \mathrm{Cu}$, and $\mathrm{Fe}$ ) occupy a class of their own since they can directly donate an electron to a reactive oxygen species. However, they mainly serve as cofactors to antioxidant enzymes just like small intracellular molecules like glutathione. Their antioxidant role is attributed to their contribution in an enzymatic reaction: metals stabilize the enzyme; Glutathione for example, serves as substrate to the glutathione peroxidase (GPx) reaction.

\subsection{Antioxidant Enzymes}

Enzymes are biological macromolecules, protein in nature with catalytic properties. The major antioxidant enzymes in the human lung are glutathione peroxidase (GPX), Superoxide dismutase (SOD) and catalase (CAT) [10] which inactivate reactive oxygen species into intermediates [40]. These enzymes are metallo-proteins which exist in various forms in the human tissues and organs.

(I). Superoxide dismutase (SOD): Superoxide dismutase, responsible for the dismutation of the primary oxidant superoxide anion $\left(\mathrm{O}_{2}^{\circ}\right)$, exists in three forms which are $\mathrm{CuZn-SOD}, \mathrm{Mn}-\mathrm{SOD}$ and EC-SOD widely distributed in the human lungs [10]. EC-SOD is primarily localized in the extracellular matrix, mostly in portions rich in type 1 collagen fibres and around pulmonary and systemic vessels, but the bulk of superoxide scavenging activity is attributed to CuZn-SOD and Mn-SOD [10].

(II). Catalase (CAT): Hydrogen peroxide (H2O2) that results from the action of SOD or oxidases is reduced by catalase or glutathione peroxidase $(\mathrm{GPx})$ to water $(\mathrm{H} 2 \mathrm{O} 2)$ [10].

(III). Case study: catalytic mechanism of glutathione peroxidase: Glutathione peroxidases (GPx), present in the cytoplasm of cells [41], are a group of selenoproteins [42, 43], catalyze the reduction of harmful peroxides in the presence of the tripeptide glutathione (GSH) as the thiol cofactor [43]. The catalytic mechanism involves the following redox reactions at the selenium centre of the active site selenocysteine residue $[42,43]$ : the selenol moiety $(\mathrm{E}-\mathrm{SeH})$ at the active site reacts with peroxide ( $\mathrm{H} 2 \mathrm{O} 2)$ and undergoes oxidation to generate the selenic acid (E-SeOH) with the reduction of peroxides. In the presence of thiol cofactor such as GSH, the selenic acid produces the corresponding selenyl sulfide intermediate (E-SeSG). Nucleophilic attack of a second molecule of GSH at the Se-S bond regenerates the active site with the release of the oxidized form of glutathione (GSSG) which, in the presence of an NADPHdependent glutathione reductase (secondary antioxidant enzyme) is transformed to its reduced form. The overall catalytic cycle is resumed in the following diagram:

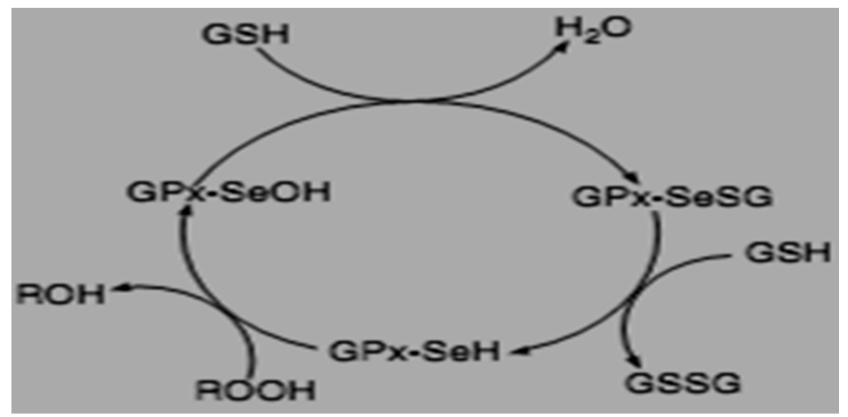

Figure 2. Catalytic cycle of glutathione peroxidase [42].

The reactions catalyzed by the three enzymes are summarized in the following table:

Table 1. Enzymatic antioxidants and their reactions [10].

\begin{tabular}{ll}
\hline Enzyme & Reaction catalyzed \\
Superoxide & $\mathrm{Mn}(\mathrm{n}+1)+-\mathrm{SOD}+\mathrm{O} 2 \rightarrow \mathrm{Mnn}+-\mathrm{SOD}+\mathrm{O} 2$ \\
dismutase (SOD) & $\mathrm{Mn}+-\mathrm{SOD}+\mathrm{O} 2+2 \mathrm{H}+\rightarrow \mathrm{Mn}(\mathrm{n}+1)+-\mathrm{SOD}+\mathrm{H} 2 \mathrm{O} 2$ \\
& $2 \mathrm{H} 2 \mathrm{O} 2 \rightarrow \mathrm{O} 2+\mathrm{H} 2 \mathrm{O}$ \\
Catalase (CAT) & $\mathrm{H} 2 \mathrm{O} 2+\mathrm{Fe}(\mathrm{III})-\mathrm{E} \rightarrow \mathrm{H} 2 \mathrm{O}+\mathrm{O}=\mathrm{F}(\mathrm{IV})-\mathrm{E}(+)$ \\
& $\mathrm{H} 2 \mathrm{O} 2+\mathrm{O}=\mathrm{F}(\mathrm{IV})-\mathrm{E}(+)+\mathrm{O} 2 \rightarrow \mathrm{H} 2 \mathrm{O}+\mathrm{Fe}(\mathrm{III})-\mathrm{E}+\mathrm{O} 2$ \\
Glutathione & $2 \mathrm{GSH}+\mathrm{H} 2 \mathrm{O} 2 \rightarrow \mathrm{GSSG}+2 \mathrm{H} 2 \mathrm{O} 2$ \\
peroxidase $(\mathrm{GPx})$ & $2 \mathrm{GSH}+\mathrm{ROOH} \rightarrow \mathrm{GSSG}+\mathrm{ROH}+\mathrm{H} 2 \mathrm{O}$ \\
\hline
\end{tabular}

\subsection{Vitamins}

Vitamins are a group of organic molecules required in small amounts as part of our diet for a healthy living. They are classified as either fat-soluble or water-soluble vitamins; however, this classification, based on their absorption and transportation means has nothing to do with their antioxidant properties which remain the same. Vitamins E and Care the main antioxidant vitamins working synergistically in the water and oily parts of the cells.

(I). Vitamin E ( $\alpha$-tocopherol)

(a). Structure and location of vitamin E: $\alpha$-tocopherolis a fat-soluble vitamin mostly documented because of its abundance in the human body and its higher antioxidant potential compared with other isomeric forms [20,44]. It is composed of a long chain attached at position 2 of a chromane ring, general characteristic of the tocopherol family [44].Vitamin E is amphipathic, with its lipophilic 
isoprenoic side chain interacting with membrane lipids and the polar chromanol ring exposed to the membrane surface [44], a positioning that enables it to tackle any eventual free radical before it gets in contact with the membrane lipids.

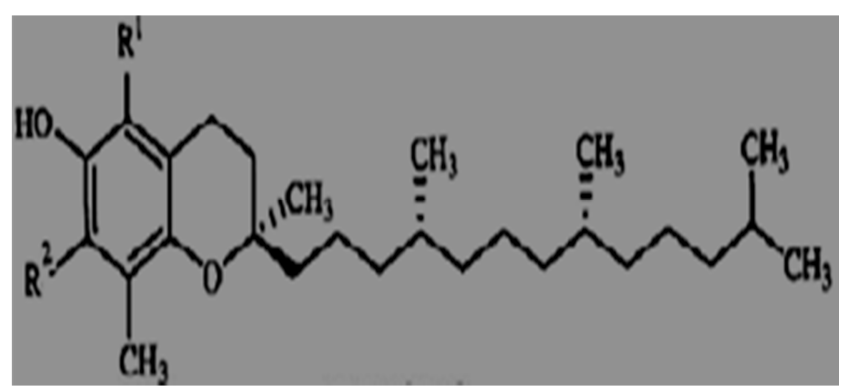

Figure 3. Vitamin E ( $\alpha$-tocopherol): R1 and R2 =CH3 [44].

(b). Antioxidant action of vitamin E: The antioxidant function of this vitamin is attributed to the protection of membrane lipids from oxidation and the direct scavenging of free radicals and this, through the chromanol group [44].Epidemiologic studies reveal that high plasma concentrations of vitamin E corresponds to a lower risk of cardiovascular events [44] because, associated to low density lipoproteins (LDL), it protects them from oxidation.

(c). Ascorbic acid (vitamin C)

\subsection{Structure and Location of Vitamin C}

Vitamin C is a water-soluble dibasic acid with an enediol group built into a five-membered heterocyclic lactone ring [45]. It is found in the water-soluble compartments of the body such as the cytosol, plasma, and extracellular fluid [45].

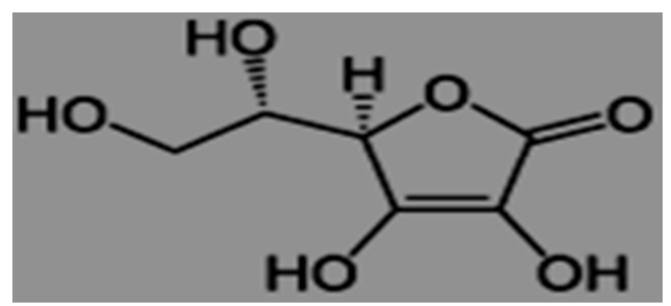

Figure 4. Vitamin C (ascorbic acid) [10].

\subsection{Antioxidant Action of vitamin C}

There are two major functions of vitamin C [45]: first, it directly reacts with, and inactivates free radicals in the compartments in which it is found; secondly, it acts synergistically with vitamin $\mathrm{E}$ to prevent LDL oxidation by vascular endothelial cells, thus preventing platelets adhesion to endothelium which is an important step in the initiation of atherosclerosis. Its synergistic action with vitamin $\mathrm{E}$ is due to its implication in the regeneration of vitamin E. by so doing, ascorbic acid on its turn is oxidized to a long-lived radical, the semi dehydroascorbyl radical which, in the presence of an NADH-dependent semi dehydroascorbate reductase or a glutathione-dependent reaction is converted to the reduced form [45].

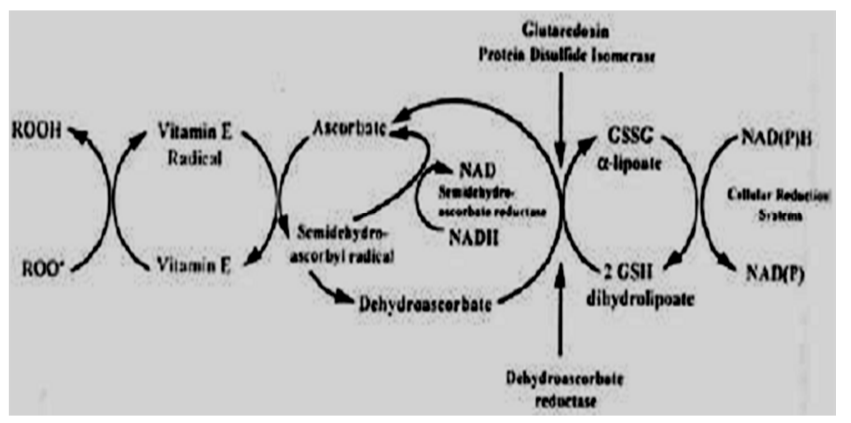

Figure 5. Pathways for the regeneration of vitamins $E$ and C [45].

\subsection{Phytochemicals}

Phytochemicals are a group of bioactive [46, 47],nonnutritive chemicals [48] naturally occurring in plant parts and conferring to the plant protection against diseases and external attacks [43].They can act alone, in combination or in conjunction with vitamins and other nutrients in food to prevent, halt, or lessen disease [48].

(I). Polyphenols

(a). generalities on polyphenols: Polyphenols(also called phenolic compounds) are phytochemicals of biological interest that have more than one phenolic hydroxyl group attached to one or more benzene rings $[45,49,50]$ and highly documented due to their structural diversity $[45,51]$. They are responsible for the major organoleptic characteristics of plant-derived foods and beverages, especially the color and taste properties [51].They can be divided into several groups with the flavonoids being the most popular group because of their structural diversity. Their structure is based on that of flavone with a common C6-C3-C6structure consisting of 2 aromatic rings ( $\mathrm{A}$ and $\mathrm{B}$ ) linked through a three-carbon chain, usually organized as an oxygenated heterocycle [52, 53]. Depending on the modifications of the central carbon ring, they can be divided into different structural classes which include flavonols, flavones, flavon-3-ols, flavanones, isoflavones, and anthocyanidins [54].

Polyphenols have gained much attention in medical research because of their use as prophylactic and therapeutic agents in many diseases this, thanks to their antioxidant [50] and indirect cytoprotective effects [49].

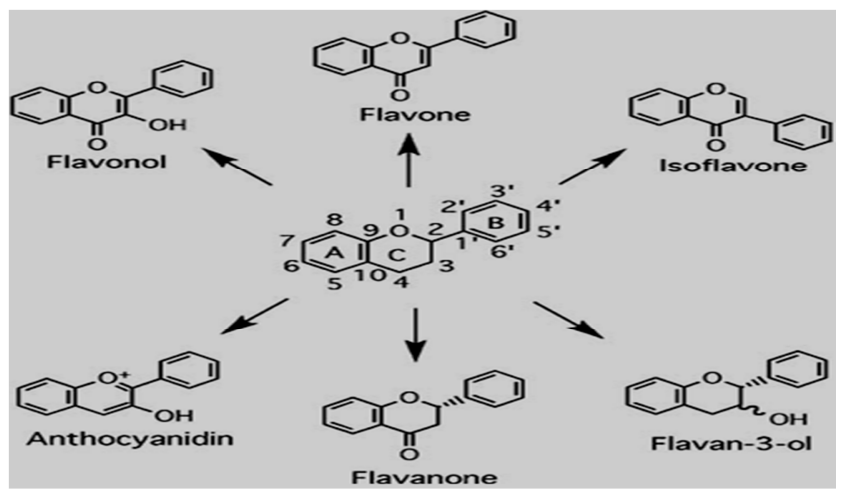

Figure 6. Structures of the main flavonoid subgroups [54].

(b). Antioxidant action of polyphenols: Reduced forms of 
plant phenolic compounds exhibit strong antioxidant capacities by scavenging a wide range of free radicals [49] unlike their vitamin counterparts which do not have multiple hydrogen and electron-donating groups on their side chains. Their antioxidant activities also differs from that of their vitamin counterparts in that having no recycling mechanisms in animals [55], questions usually arise as to the stability of the aroxyl radical that results from their free radical scavenging. The stability of the aroxyl radicals results from the disproportionation reaction of the radical to render non radical species [55]. Disproportionation is a chemical phenomenon whereby a substance undergoes simultaneous oxidation and reduction. The structural requirements for this radical stabilization are: the presence of the catechol moiety, the 2, 3double bond in conjugation with a 4-oxo function, and the additional presence of 3 -and 5-hydroxyl groups [55, 56].The above-mentioned physicochemical aspects make some polyphenols good chelators of metal ions [53, 55] such as copper and iron that enhance lipid oxidation [53]. The disproportionation mechanism is demonstrated with the following reaction using resveratrol (3, 5, 41-trihydroxy-transstilbene), a type of natural phenol, and a phytoalexin produced naturally by several plants when under pathogenic attacks [57].

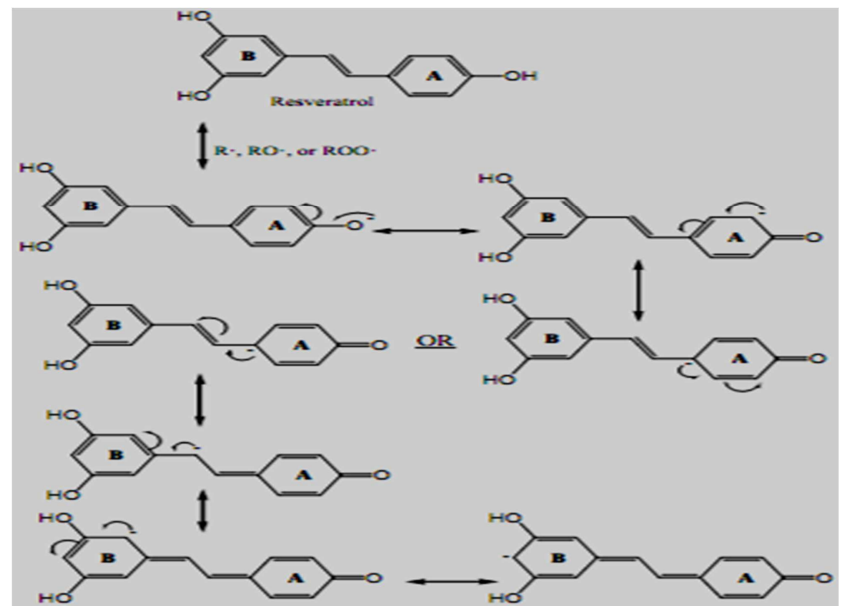

Figure 7. Proposed mechanism of resveratrol [57].

(c). Cytoprotective action of polyphenols: The cytoprotective effects of plant phenolic compounds initially attributed to their antioxidant properties were later suggested to be probably due to their direct interaction with cellular components with the resultant triggering of a series of responses that modulate the redox status of the cells, protecting them from potential oxidants [49].Recent investigations attribute this action to the induction of phase II and antioxidant enzymes thereby increasing their activities [49]. This claim is based on the finding that phenolic compounds such as butylatedhydroxyanisole (BHA), butylatedhydroxytoluene (BHT), etc. potently inhibited the toxicity and carcinogenicity of chemical carcinogens (inducers of enzymes) [49].

\subsection{Sources of Natural Antioxidants}

Natural antioxidants are primarily found in plants, mostly in such plant products like fruits and vegetables [58]. Animals depend on plant-based products to obtain antioxidants, but animal-derived products contain insignificant amounts compared to plants [59]. Natural antioxidants come from plant-based products like fruits, vegetables, cereals and legumes, beverages and spices and animal derived foods.

Fruits are food products highly appreciated by nutritionists and dieticians due to their high content of vitamins and minerals [59]. A wild plants fruit like berries are very rich in vitamin $\mathrm{C}$ and phenolic compounds predominantly anthocyanin and ellagic acid [59]. Among the vegetables, best sources of antioxidants are tomatoes, red pepper, brassica vegetables (white cabbage, kale, broccoli sprouts etc.), onion, garlic and red beet, with flavonoids group dominating among the polyphenols [59, 60]. Cereals and legumes though with a huge diet share, they are not very rich sources of antioxidants; they contain only phenolic compounds [59]. Beverages such as coffee, tea, red wine as well as herbs and spices are rich sources of antioxidants. In teas, catechins are the predominant phenolic compounds which content varies with respect to plant source and postharvest treatment methods [59]. Spices and herbs due to their richness in antioxidants are valuable food additives not only due to their ability to give taste and smells to foods but also because of their ability to act as food preservatives [59].

Animal-derived food products supply: amino compounds which antioxidant activity is mainly linked with amino acids with thiol groups, vitamin $\mathrm{E}$ ( $\alpha$-tocopherol) located mainly in the bi-lipid layer of the cell membrane and the carotenoids mainly located in the liver [59].

A recent study reveals the oils of the allium products onion and garlic to be good sources of multifunctional antioxidants [61]. The focus in medicinal plants research being to find a more cost-effective treatment which is reachable to all strata of our society, these allium products in Cameroon are not easily affordable by the lower class which constitutes the bulk of the population. Above all, the impossibility of cultivating them in many parts of the country accounts for this. Besides, even the most privileged who can afford these products frequently use them only in minimal quantities as ingredients in their cuisine with the resultant negligible or no antioxidant impact. Another plant which is gaining popularity today is Hibiscus sabdariffa of the sabdariffa Linn variety (Roselle) commonly called 'foléré' in the Fulfulde language of Northern Cameroon.

\section{Hibiscus Sabdariffa Linnaeus (Roselle)}

\subsection{Botanical Description}

Roselle is an erect highly ramified annual shrub that belongs to the family of Malvaceae [62-67]. The plant has a deep, penetrating tap root with a dark- green- red stem that is nearly smooth, cylindrical, with variable heights which can attain up to 3.5 meters $[65,67]$. The leaves are alternate, 7.5 $12.5 \mathrm{~cm}$ long, green with reddish veins and long or short 
petioles [65]. Leaves of young seedlings and upper leaves of older plants are simple; lower leaves are palmately divided into 3-7 lobes, with serrated (toothed) margins $[65,66]$. The flowers singly born in the leaf axils are up to $12.5 \mathrm{~cm}$ wide, yellow or buff with a rose eye which turn pink as they wither at the end of the day [65]. The calyx, purple-red in color [64] is made of 5 large sepals with an epicalyx of 8-12 slim, pointed bracts (or bracteoles) around the base, and begin to enlarge at the end of the day, $3.5-5.7 \mathrm{~cm}$ long, fully enclosing the fruit [65]. The fruit is a velvety capsule, $1.25-2 \mathrm{~cm}$ in length, which is green when immature, composed of 5 valves each of which has 3-4 seeds.
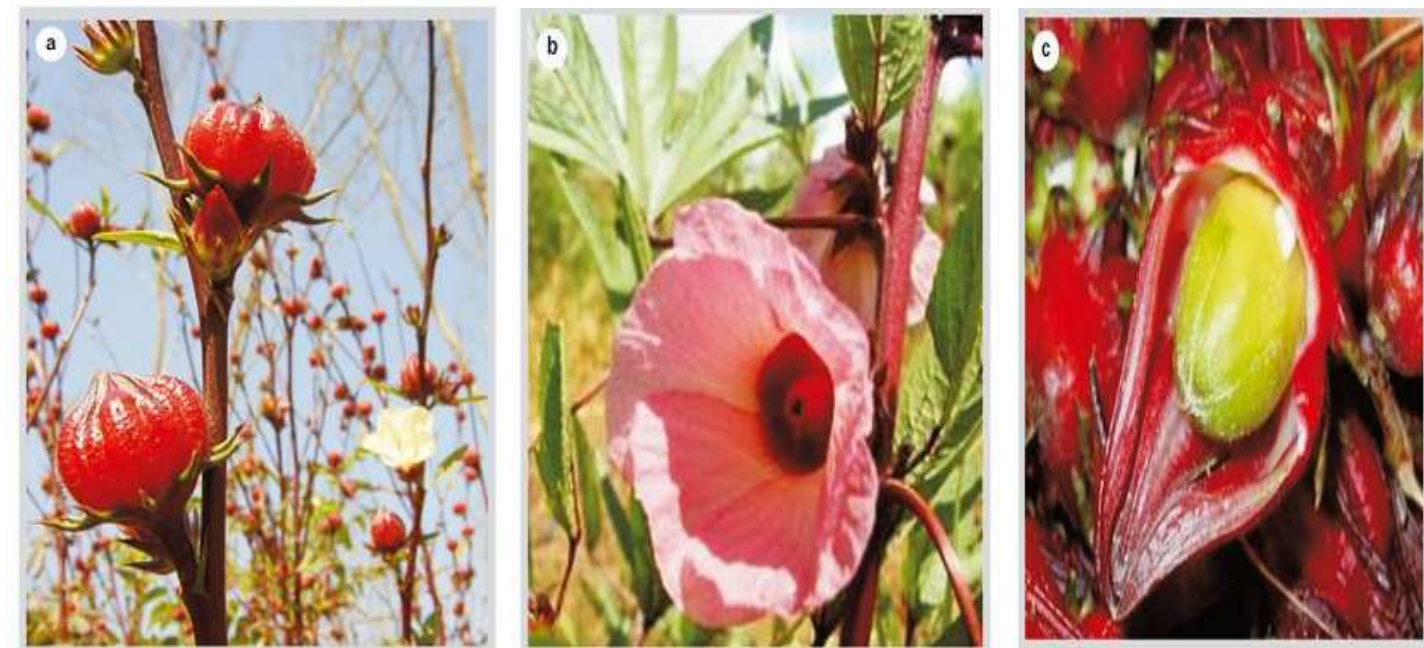

Figure 8. Photo of Hibiscus sabdariffa, sabdariffa Linn variety: (a) stalk, leaves and calyces; (b) flower; (c) fruit and calyces [62].

\subsection{Cultivation}

Hibiscus sabdariffa Linnaeus is an annual shrub that is widely cultivated in the tropical regions of the world, usually between the months of April and November [65]. In some areas around the world, it is cultivated as a home garden crop; cultivation is done using the seeds, rooting or shoot cuttings on a well-drained soil[65] (root and stem rot occur when water content in an irrigated field is not checked), with an annual rainfall of 130-260 $\mathrm{mm}$ in the first 3-4 months of growth $[65,66]$. The plant is tolerant to warm and humid climate [66]. Dry weather is favorable during the later months of growth [66].Root and stem rot, major problem of Roselle cultivation are prevented by monitoring the water content in irrigated fields and by avoiding mixed cultivation with other crops that are susceptible to root and stem rot [62].

\subsection{Harvesting of Calyces}

Harvesting begins when the flowers have dropped off, but before which the seed pod must have dried open [66]. It is done as from late November when there is little or no rains and humidity as these factors negatively influence the quality of the harvest [66]. It is an intensive hand labor in which calyces are singly picked at the appropriate stage; fully developed calyces are peeled from the fruit by hand [66]. The time lapse between planting and harvesting (when fruits are matured) is usually 5 months [66].

\subsection{Post-Harvest Treatment of Calyces}

Scouring is the process that usually follows harvesting. It is a complex manual procedure which is aimed at separating the calyx from the capsule. In some settings, this process is facilitated by cutting the base of the flower stalk with a knife releasing the capsule with a resultant circular closed calyx.

Drying usually follows shelling. It is aimed at reducing the moisture content of calyces to minimal value that can inhibit microbial or fungal proliferation. There is no actual conventional drying method as it varies with respect to the economic situation of. Traditionally, drying with adequate ventilation employs woven nylon mats which prevents the calyces from being sunbaked, which may affect the quality especially as the anthocyanin are degraded by excessive heat treatment [62]. Storage in ventilated polypropylene bags under dry conditions maintains the quality of calyces.

\subsection{Phytochemical and Nutritional Composition of Hibiscus Sabdariffalinn Calyces}

Phytochemicals are a group of non-nutrient bioactive compounds found naturally in plant parts providing protection, characteristic color, aroma and flavor in plants [68].Roselle is a potential source of vitamins, minerals, and bioactive compounds such as organic acids, phytosterols, and polyphenols, some of which are potential antioxidants [69]. the leaves contain proteins, fat, carbohydrates, fiber, ash, calcium, phosphorus, iron, $\beta$-carotene, riboflavin, niacin and ascorbate $[65,67]$. The young leaves and stems are eaten raw in salad [70]. Although the seeds are bitter and discarded in some parts of the world, studies have revealed them to be rich in proteins, reason why they are ground into meal in some parts of Africa [70].

Roselle calyces, due to their high content in organic acids, vitamin $\mathrm{C}$, and above all anthocyanin (delphinidin-3-Osambubioside, delphinidin-3-O-glucoside [myrtillin], and cyanidin-3-O-sambubioside), are the most consumed parts of the plant [62], making them the target for medical research[70]. The medicinal value is mainly due to the 
predominance of anthocyanin, potential antioxidant that is responsible for the reddish dark color of the plant parts in general $[62,70,71]$, and the calyces in particular. The anthocyanins are responsible for the protection of plants against excessive light by shading leaf mesophyll cells and also have an important role to play in attracting pollinating insects [54].Analysis of calyces also reveals flavonoids (gossypetine, hibiscetine, and sabdaretine), alkaloids, galactose, protocatechuic acid, quercetin, and stearic acid, minerals (Fe, P, Ca, Mn, Al, Mg, Na, and K) [65].Analytic studies of calyx extract reveal other secondary metabolites such as saponins, oxalates, tannins and phytates have been revealed in calyces at variable concentrations [68]. Studies using experimental animals reveal particular biological activities with each of these substances: saponins are noted for their hypoglycemic and hypocholesterolemic activity; phytates are implicated with reduced mineral absorption while oxalic acid is associated with toxicity [68].

\subsection{Traditional Methods of Extraction of Bioactive Substances from Roselle Calyces}

In pharmaceutical terms, extraction is the separation of medicinally active portions of plant tissues from the inert/inactive components by the use of selective solvents [72]. During the process, solvents diffuse into the solid plant material and dissolve substances with similar polarity [72]. Decoction is the popular traditional method of extraction of Roselle calyces. It is used for the extraction of water-soluble and heat-stable constituents from crude plant material by boiling it in water followed by cooling, straining and passing sufficient cold water through the extract to produce the required volume [72]. Depending on the aim of the extraction, the method can be modified. For Roselle calyces, they are usually exploited in the preparation of a beverage which involves soaking dried calyces in hot or warm water for a few minutes, filtering, sweetening, flavoring, and packaging $[62,64,73]$. It should be noted that the ratio weight (calyces)/volume (H2O) [w/v\%] is not standard [73], and depends on one's desire. Locally, 200 grams of the calyces is boiled in $200 \mathrm{~mL}$ of tap water at $100 \mathrm{oC}$ for 15 minutes and the mixture is pounded with a pestle and filtered [71]. Also of importance is the fact that, for whatever extraction method used heat treatment destroys some of the antioxidant capacity. The main parameters used to evaluate the quality of the beverage are color intensity, degree of sweetness, and the overall pleasant taste [73]. This beverage is highly appreciated for its taste and is given various appellations in different parts of the world. In Cameroon for example, it is called 'foléré' (in Fulfulde).

\subsection{Toxicological Findings About Roselle Calyx Juice}

The worries usually expressed about pharmacological use of plant extracts is that of their toxic effects. Research findings have revealed that the problem usually posed with consumption of natural products results from overdose, but that, considering the low bioavailability of their bioactive compounds, regular, moderate consumption poses no threat to health since they are supplied with protective ingredients [61]. Besides, little or no information is currently available about the toxicity of Hibiscus sabdariffa ever since its popular use in pharmacology [62].

\section{Conclusion}

Results from our phytochemical analysis confirm available literature claim that the flavonoids are the most abundant of all the classes of polyphenol. In our study, flavonoids constitute approximately $75 \%$ of total polyphenols present in the calyx extract. Calyx juice of Hibiscus sabdariffa Linn Possesses some beneficial health effects when associated with antiretroviral treatment; however, presence of anti nutrients should never be neglected when consuming this natural product.

\section{References}

[1] Esra B., Umit M. S., Cansin S., Serpil E. and Omer K. 2012. Oxidative stress and antioxidant defense. WAO Journal 5:9-19.

[2] Isaac K. Q. 2012. Oxidative stress in human health and disease, insight and control of infectious disease in global scenario, DR. Roy Priti (Ed.), ISBN: 978-953-51-0319-6, In Tech, Available from: http://www.intechopen.com/books/insight-and-control-ofinfectious-disease-in-global-scenario/oxidative-stress-inhealth-and-disease.

[3] Gora D., Praveen S., Shiv G. (July-Sept 2012). Oxidative stress-induced response of some endogenous antioxidants in schizophrenia. Indian Journal of Clinical Biochemistry 27(3):278-283. DOI: 10.1007/s12291-012-0193-z.

[4] Xuejuan Y., Jun C., Chunxiao Z., Hua C., and Youbin L. 2012. Evaluation of antioxidant activity of fermented soybean meal extract. African Journal of pharmacy and Pharmacology [online] 6 (24):1774-1781. Available from: http://www.academicjournals.org/AJPP. DOI: 10.5897/AJPP12.392.

[5] Zhang Y., Dawson V. L., Dawson T. M. 2000. Oxidative stress and genetics in the pathogenesis of Parkinson's disease. Neurobiol Dis 7:240-250.

[6] Vishwanath M. S. Introduction to clinical nutrition.2nd ed. [Online]. New York: Marcel Dekker, Inc.; 2003. Available from: http://www.dekker.com.

[7] Munmee D., Bishnu P. S., Giasuddin A., Cakkalur B. N., Monjoy K. C. 2012. In vitro anti oxidant activity and total phenolic content of Dillenia indica and Garcinia penducalata, commonly used fruits in Assamese cuisine. Free Radicals and Antioxidants 2(2). DOI: 10.5530/ax.2012.2.6.

[8] Abheri D. S., Anisur R. M., and Ghosh A. K. 2010. Free radicals and their role in different clinical conditions: An overview. International Journal of Pharmaceutical Sciences and Research 1(3):185-192.

[9] Noori S. 2012. An overview of oxidative stress and antioxidant defensive system. 1:413. DOI: 10.4172/scientificreports. 413 . 
[10] Amit K., Priyadarsini K. I. 2011. Free radicals, oxidative stress and importance of antioxidants in human health. Journal of Medical Allied Sciences [online] 1(2):53-60. Available from: www.jmas.in. [Accessed 31st March 2013]

[11] Lien A P. H., Hua H., Chuong P. H. 2008. Free radicals, antioxidants in disease and health. Journal of Biomedical Sciences [online] 4(2):89-96.available from: http://www.ijbs.org. [Accessed 1st November 2013]

[12] Upma G., Anju J., Parul S., Sarita B., Rajiv G., Arvind S. (April-June 2012). Free radical status in retinopathy of prematurity. Indian Journal of Clinical Biochemistry 27(2):196-199.

[13] Gerhard Krauss. Biochemistry of signal transduction and regulation.3rd ed. Wiley-VCH Verlag. $\mathrm{GmbH}$ and Co. KGaA, Weinheim; 2003.

[14] Manzoor A., Nida S., Tariq M., Naheed B., Shamshad A. (OctDec 2012). Evaluation of oxidative stress and DNA damage in benign prostatic hyperplasia patients and comparison with controls. Indian Journal of Clinical Biochemistry 27(4):385388.

[15] Lizette G. D. V., Rosario G. H., Jorge P. A. 2013. Oxidative stress associated to disease progression and toxicity during antiretroviral therapy in Human Immunodeficiency Virus infection. Journal of Virology and Microbiology [online] 2013:15. Available from: http://www.ibimapublishing.com/journals/JVM/jvm.html. DOI: 10.5171/2013.279685. [Accessed14th February 2014]

[16] Bo J., Alok R. K., Lynette K. R., Valeria Y. H., James H. Z., et al. 2010 October. Antiretroviral induce endothelial dysfunction via an oxidant-dependent pathway and promote neointimal hyperplasia. Toxicological Science 117(2): 524-536.

[17] Anthony H. K., Ashok A. 2011. Oxidants and antioxidants in the pathogenesis of HIV/AIDS. The Open Reproductive Science Journal 3: 154-161. DOI: 10.1186/1742-6405-3-19. [Accessed 7th October 2013]

[18] Seyed A. A., Seyedeh F. M., and Ebrahim B. 2012. Antioxidants: A few key points. Annals of Biological Research [online] 3(8):3968-3977. Available from: http//www.scholarsresearchlibrary.com. [Accessed 14th June 2014]

[19] Saikat S., Raja C., Sridhar C., Reddy Y. S. R., Biplab D. 2010. Free radicals, antioxidants, diseases and phytomedicines: Current status and future prospect. International Journal of Pharmaceutical Sciences Review and Research [online] 3(21):091-100. Available from: $\mathrm{http} / / \mathrm{www}$. globalresearchonline.net

[20] Erin E. B. and Julia L. B. 2009. Antioxidant activity of sulfur and selenium: A review of reactive oxygen species scavenging, glutathione peroxidase, and metal-binding antioxidant mechanisms. Cell Biochemistry and Biophysics 55:1-23. DOI: 10.1007/s12013-009-9054-7

[21] Krishna P. B., Debasish B. and Govindasamy M. 2013. Synthetic glutathione peroxidase mimics: Effect of nucleophilicity of the aryl thiol cofactor on the antioxidant activity. Indian Journal of Chemistry 52:1019-1025.

[22] Maria L. C. 2010. An update of vitamin E, tocopherol and tocotrienol- perspectives: A review. Molecules [online] 15:2103-2113. Available from: http//www.mdpi.com/jornal/molecules. DOI: 10.3390/molecules.15042103. [Accessed11th August 2014]
[23] Aysun H. 2009. An overview of ascorbic acid biochemistry. Journal of Faculty of Pharmacy, Ankara 38(3):233-255.

[24] Vittorio C., Marzia P., Carolin C., Raffaella C., Fabio D. D., Giovanni P., et al. Phenolics in aging and neurodegenerative disorders. In: Cesar G. Fraga (Ed.). Plant phenolics and human health. Hoboken, New Jersey: John Wiley and sons Inc.:2010.p.427-444.

[25] James H. D. 2012. Phytochemicals: Extraction Methods, Basic Structures and Mode of Action as Potential Chemotherapeutic Agents, Phytochemicals-A Global Perspective of Their Role in Nutrition and Health, Dr. Venketshwer Rao (Ed.), ISBN: 978953-51-0296-0, InTech, Available from: http//www.intecopen.com/books/phytochemicals-a-globalperspective-of-their-role-in-nutrition-and-health/phytochemicalsextraction-methods-basic-structures-and-mode-of-action-aspotential-chemotherapeutic-agents.

[26] Satyanand T., Gunjan S., Anamika S., Gulshan A. 2010. Phytochemicals as candidate therapeutics: An overview. International Journal of Pharmaceutical Sciences Review and Research [online] 3(1):53-55. Available from: $\mathrm{http} / / \mathrm{www}$.globalresearchonline.net. [Accessed 11th August 2014]

[27] Siwang Y., Ka L. C., Wenge L., and Ah-ng K. Plant phenolic compounds: Modulation of cytoprotective enzymes and Nrf2/ARE signaling. In: Cesar G. Fraga (ed.) Plant phenolics and human health. Hoboken, New Jersey: John Wiley and sons Inc.; 2010. P. 402-409.

[28] Sanda V. K. B. B., Maja B. S. and Marija B. 2012. Plant polyphenols as antioxidants Influencing the Human Health, Phytochemicals as Nutraceuticals-Global Approaches to Their Role in Nutrition and Health, Dr. Venketeshwer Rao (Ed.), ISBN:978-953-51-0203-8, InTech, Available from: http//www.intechopen.com/books/phytochemicals-asnutraceuticals-global-approaches-to-their-role-in-nutrition-andhealth/plant-polyphenols-as-antioxidants-influencing-the-humanhealth.

[29] Tapas A. R., Sakarkar D. M. and Kakde R. B. 2008. Flavonoids as nutraceuticals: A review. Tropical Journal of Pharmaceutical Research [online] 7(3):1089-1099. Available from: http//www.tjpr.org.

[30] Zuzana K. 2011. Toxicological aspects of the use of phenolic compounds in disease prevention. Interdisciplinary Toxicology [online] 4(4):173-183. Available from: http//www.intertox.sav.sk and http//www.versita.com/science/medicine/it/ DOI: 10.2478/v10102-011-0027-5. [Accessed 11th August 2014]

[31] Evelyn B. R., Maxima E. F., Delia B. R. A. and Jaime A. F. 2006. Phytochemicals and functional foods. Current situation and prospect for developing countries. Segurança Alímentar $e$ Nutricional, Campinas 13(1):1-22

[32] Indu B. J. and Alan C. Dietary flavonoids and phenolic compounds. In: Cesar G. Fraga(Ed.). Plant phenolics and human health. Hoboken, New Jersey: John Wiley and sons Inc.:2010.p.1-39.

[33] Cesar G. F., Gulcin S. C., and Monica G. Biochemical actions of plant phenolics compounds: Thermodynamic and kinetic aspects. In: Cesar G. Fraga (ed.) Plant phenolics and human health. Hoboken, New Jersey: John Wiley and sons Inc.; 2010. P. 91-103.

[34] Harleen K. S., Bimlesh K., Sunil P., Prashant T., Manoj S., Pardeep S. 2011. A review of phytochemistry and pharmacology of flavonoids. International Pharmaceutica Sciencia [online] 1(1):25-41. Available from: http//www.ipharmsciencia.com. 
[35] Mohamed A. H. 2011. A convenient mechanism for the free radical scavenging activity of resveratrol. International Journal of Phytomedicine [online] 3:459-469. Available from: $\mathrm{http} / /$ www.arjournals.org/index.php/ijpm/index. [Accessed 14th June 2014]

[36] Ajit B. P. and Asha S. J. 2013. Flavonoids, an antioxidant: A review. International Journal of Pharmaceutical and Biological Sciences Research and Development [online] 1(2):07-20. Available from: http://www.ijpbsrd.com. [Accessed 14th June 2014]

[37] Elżbieta S., Ewa C., Kinga T. 2008. The sources of natural antioxidants. Acta Sci. Pol., Technol. Aliment. 7(1):5-17.

[38] Dilip K. P. and Preeti V. 2013. Flavonoids: A powerful and abundant source of antioxidants. International Journal of Pharmacy and Pharmaceutical Sciences 5(3):95-98

[39] Augusti K. T., Regi J., Sajitha G. R., Paul A. (Jan-Mar 2012). A rethinking on the benefits and drawbacks of common antioxidants and a proposal to look for the antioxidants in allium products as ideal agents: A review. Indian Journal of Clinical Biochemistry 27(1): 6-20.

[40] Mady C., Manuel D., Mama S., Augustin N., Max R., Oumar S. 2009. Le bissap (Hibiscus sabdariffa L): composition et principales utilisations. Fruits [online] 64(3): 179-193. Available from: http://www.fruits-journal.org or http://dx.doi.org/10.1051/fruits/2009013. [Accessed 7th October 2013]

[41] Germaine Y., Jean-Bosco T., Clergé T. 2009. Protein, carbohydrate, fat and energy content of "Ready-to-eat-Foods" in Cameroonian Sahel's Region.Journal of Food Technology $7(1): 1-4$.

[42] Claudia S. G., Fidel T. V. B., Anna E. O. R., José A. G.B. 2012. Antioxidant properties and color of Hibiscus sabdariffa extracts. Ciencia e Investigación Agraria [online] 39(1):79-90. Available from: www.rcia.uc.cl. [Accessed 7th October 2013]

[43] Mahadevan N., Shivali and Pradeep K. 2009. Hibiscus sabdariffa Linn- An overview. Natural Product Radiance 8(1):77-83.
[44] Bahaeldeen B. M., Abdelatif A. S., and Abdel hafiz A. D. 2012 Roselle (Hibiscus sabdariffa L.) in Sudan, cultivation and their uses. Bulletin of Environment, Pharmacology and Life Sciences [online] 1(6):48-54. Available from: www.bepls.com. [Accessed 16th February 2014]

[45] Amin I., Emmy H. K., Halimatul S. M. N. 2008. Roselle (Hibiscus sabdariffa L.) seeds- nutritional composition, protein quality and health benefits. Food 2(1):1-16.

[46] Ijeomah A. U., Ugwuona F. U. and Abdullahi H. 2012. Phytochemical composition and antioxidant properties of Hibiscus sabdariffa and Moringa oleifera. Nigerian Journal of Agriculture, Food and Environment 8(1):10-16.

[47] Alaa G. A-H. 2012. Antioxidant and anti bacterial activities of Hibiscus sabdariffa L. extracts. African Journal of Food Science [online] 6(21):506-511. Available from: http://www.academicjournals.org/AJFSDOI:

10.5897/AJFS12.099. [Accessed 7th October 2013]

[48] Norhaizan M-E., Fong S. H., Amin I., Chew L. Y. 2010. Antioxidant activity in different parts of the Roselle (Hibiscus sabdariffa L) extracts and potential exploitation of the seeds. Food Chemistry [online] 122(2010): 1055-1060. Available from: http://www.elsevier.com/locate/foodchem. [Accessed 7th October 2013]

[49] Mowuogwu F. O., George B. O. 2008. Comparative antioxidant activity of Hibiscussabdariffaand ascorbic acid on ferrous sulfate-induced oxidative stress in Clarian gariepinus. East Central African Journal of Pharmaceutical Sciences 11(2008): 39-42.

[50] Prashant T., Bimlesh K., Mandeep K., Gurpreet K., Harleen K. 2011. Phytochemical screening and extraction: A review. International Pharmaceutica Sciencia [online] 1(1):98-106. Available from: http//www.ipharmsciencia.com. [Accessed 11th August 2014]

[51] Bolade M. K., Oluwalana I. B., and Ojo O. 2009. Commercial practice of Roselle (Hibiscus sabdariffa L.). Beverage production: Optimization of hot water extraction and sweetness level. World Journal of Agricultural Sciences 5(1):126-131. 